\title{
A low-cost environmentally friendly approach to isolate lignin containing micro and nanofibrillated cellulose from Eucalyptus globulus bark by steam explosion
}

\author{
Saad NADER ( $\square$ saad.nader@lgp2.grenoble-inp.fr) \\ LGP2: Laboratoire Genie des Procedes Papetiers https://orcid.org/0000-0002-8726-5495 \\ Nicolas BROSSE \\ LERMAB: Laboratoire d'etudes et de recherche sur le materiau bois \\ Malek KHADRAOUI \\ LGP2: Laboratoire Genie des Procedes Papetiers \\ Cecilia FUENTEALBA \\ unidad de desarrollo tecnologico \\ Isabelle ZIEGLER-DEVIN \\ LERMAB: Laboratoire d'etudes et de recherche sur le materiau bois \\ Fabienne QUILÈS \\ LCPME: Laboratoire de Chimie Physique et Microbiologie pour les Materiaux et l'Environnement

\section{Evelyne MAURET} \\ LGP2: Laboratoire Genie des Procedes Papetiers \\ Sofiane EL KIRAT CHATEL \\ LCPME: Laboratoire de Chimie Physique et Microbiologie pour les Materiaux et l'Environnement
}

\section{Research Article}

Keywords: lignin-containing microfibrils, Steam explosion, Eucalyptus globulus bark, lignin, Alkali treatment

Posted Date: November 2nd, 2021

DOI: https://doi.org/10.21203/rs.3.rs-1025848/v1

License: (c) (1) This work is licensed under a Creative Commons Attribution 4.0 International License. Read Full License 


\section{Abstract}

Micro- and Nano-Fibrillated Cellulose (MNFCs) have gained an increasing attention due to their remarkable properties but their production usually requires an intensive multi-step process. This study proposes to find a novel approach involving steam explosion for the production of lignin-containing micro- and nano-fibrillated cellulose (L-MNFCs) using Eucalyptus globulus bark as a new lignocellulosic feedstock. Eucalyptus globulus bark was first pre-treated in alkali conditions by steam explosion in alkaline conditions $\left(200^{\circ} \mathrm{C}, 8 \mathrm{~min}\right)$ or by conventional alkaline cooking in a rotating autoclave $\left(170^{\circ} \mathrm{C}, 60 \mathrm{~min}\right)$, refined and then grinded until the formation of gels. The chemical composition (lonic chromatography, FTIR-ATR) of the pulps and morphology of the products (Morfi Neo, Optical and Atomic Force Microscopies (AFM), suspension turbidity) have been studied. Nanopapers were produced from lignin-containing microfibrils to investigate the mechanical properties. Results obtained showed that steam explosion produced pulps with slightly higher lignin content $(\approx 9 \%)$, containing shorter fibers $(\approx 400 \mu \mathrm{m})$ and higher amounts of fine elements $(\approx 86 \%$ ) compared to conventional alkali cooking $(\approx 5 \%, \approx 560 \mu \mathrm{m}$ and $66 \%$, respectively). AFM images of SteamEx LMNFC gels showed a web-like structure containing lignin nanoparticles.

\section{Highlights}

\section{Highlights}

- Valorization Eucalyptus Globulus bark

- Steam explosion can replace conventional alkali cooking for pulp production.

- Steam explosion pulps contain shorter fibers and more fine elements.

- Lignin is expelled from lignocellulosic microfibers by steam explosion.

\section{Introduction}

Micro- and Nano-Fibrillated Cellulose (MNFCs) constitute a new bio-based, renewable, biodegradable and nontoxic material. MNFCs width varies between approximately 10 and $100 \mathrm{~nm}$ or even more depending on the raw material and the production process used, and their length can reach a few micrometers (TAPPI WI 3021). Owing to their high specific surface area and aspect ratio, MNFCs exhibit attractive physical and mechanical properties $(165,166)$. As a result, MNFCs can be used in different applications, i.e. in paper reinforcement (Ahola et al. 2008; Dufresne 2012), nanocomposites (Siro and Plackett 2010), packaging (Lavoine et al. 2012), aerogels (Sehaqui et al. 2011), bio-medical (Lin and Dufresne 2014), cosmetics (Ullah et al. 2016), etc. MNFCs are extracted from the wall of vegetal fibers and wood pulp was the first material used to produce them (Herrick et al., 1983). Researchers focused on the production of fully bleached MNFCs. Meanwhile, in the last years, isolation of lignin-containing micro and nanofibrillated cellulose (L-MNFC) was also investigated: different lignocellulosic feedstocks have been experimented, such as banana, pineapple, jute (Abraham et al., 2011), different wood species (Park et al., 2017), Kraft wood pulp (Wang et al. 2012), etc.

MNFCs are generally produced by combining different processes (Nechyporchuk, 2016): (1) homogenization (Herrick et al., 1983), grinding (Gane et al., 2010), refining (Henriksson et al., 2007), extrusion (Ho et al., 2015) being the most common studied processes, (2) chemical and biological pre-treatments such as carboxylation via TEMPO oxidation (Bäckström et al. 2012). Depending on the applications, post-treatments can be used to modify MNFCs, i.e. surface modification (Missoum et al. 2013). The high-energy consumption of the whole processes remains the most important obstacle for MNFCs wide use. It has been shown that the energy consumption of homogenization process significantly decreases with pre-treatments (from $70 \mathrm{MWh} / \mathrm{t}$ (Eriksen et al. 2008) to 2 $\mathrm{MWh} / \mathrm{t}$ (Lindström et al. 2011)).

Steam explosion (SteamEx) is a thermomechanical process, which is known as one of the most efficient pre-treatments of lignocellulosic materials (Sun and Cheng 2002). A batch steam explosion facility is composed of a steam generator that supplies a reactor with vapor to heat the biomass under pressure for short times. A sudden release of pressure ejects the biomass from the reactor to the explosion tank. This process is constituted of two phases: (1) steam treatment where water vapor and high temperature acts together to initiate the depolymerization of hemicelluloses and degradation of lignin, (2) explosive defibration where the sudden depressurization provokes a rupture of the fiber cell wall due to shear and compression forces caused by the evaporation of the condensed water in the biomass (Cherian et al., 2008; Jacquet et al., 2010; Nechyporchuk, 2016). Loading [MathJax]/jax/output/CommonHTML/jax.js 
It has been reported that SteamEx significantly impacts the cell wall by converting a large part of hemicelluloses into soluble sugars (Chadni et al., 2019) and by degrading the lignin through aryl-ether bond hydrolysis (Obame et al., 2019). During SteamEx treatment, the breakdown of lignin produces small fragments of melted lignin which may redeposit on the surface of the fibers. This lignin relocation has been extensively reported in the literature and microscopy images of lignin droplets have been published (Takada et al. 2019; Chandra et al. 2016). In contrast to the other cell wall components, cellulose is relatively unaffected by the treatment. It has been shown that SteamEx primarily in alkali conditions (Sauvageon et al., 2018; Sutka et al., 2013) degrades the cell middle lamella allowing the isolation of cellulosic fibers and micro-fibrils from biomass. In a pioneering work, Kessler et al. 1995 reported the production of linen from soda impregnated flax fibers by SteamEx. More recently, in our group (Sauvageon et al., 2018) we described the cottonization of hemp fibers by alkali SteamEx and the production of individual fibers with a diameter of about 20 $\mu \mathrm{m}$. Damaged fibers were also observed due to the conjugated effect of alkali degradation and steam explosion.

SteamEx has also been studied in various experimental conditions by other authors for the production of MNFCs from fibrous biomass. Cherian et al. 2010 produced MNFCs from pineapple leaves by steam treatment performed in an autoclave $(0.13 \mathrm{MPa}$ during one hour) followed by bleaching $\left(\mathrm{NaClO}_{1} \mathrm{KMNO}_{4}\right)$. Kaushik et Singh 2011 applied SteamEx (2 MPa, 4h) on wheat straw followed by bleaching $\left(\mathrm{H}_{2} \mathrm{O}_{2}\right)$, sonification and homogenization. Abraham et al. 2011 obtained MNFCs from three different biomasses (banana, jute and pineapple leaf fibers) by combining SteamEx to alkaline extraction, bleaching and acid hydrolysis. Tuzzin et al. 2016 used tobacco to extract MNFCs using SteamEx (1.2 MPa) followed by bleaching $\left(\mathrm{NaClO}, \mathrm{H}_{2} \mathrm{O}_{2}\right.$ at $\left.50^{\circ} \mathrm{C}\right)$ and grinding. Nevertheless, because of technical limitations, most of the described experiments were performed at relatively low steam pressure (around $0.1-2 \mathrm{MPa}$ ) using an autoclave. In such conditions the explosion step may be quite less efficient because it is not well controlled and/or optimized.

Economically, Eucalyptus globulus is one of the most important forest species in Chile. Harvesting of Eucalyptus generates about $30 \%$ of residues (15-25t/ha year) $10-12 \%$ of the residue volume corresponding to barks (Sartori et al., 2016). There are only few publications on the valorization of Eucalyptus bark (EB) but, recently, this resource has been considered as a new raw material for the pulp and paper industry due to its high fiber content (Miranda et al. 2012; Romaní et al. 2019). Fuentealba et al. 2016 have also demonstrated that the morphological and the physical properties of EB allow its use as an innovative insulation material.

To the best of our knowledge, no study has been conducted until now to produce L-MNFCs from Eucalyptus globulus bark. In addition, no comprehensive study has been conducted to thoroughly investigate the specific effect of the SteamEx treatment on MNFCs morphology and composition.

The aim of this study is to find a novel way to valorize the Eucalyptus globulus barks considered as a harvesting residue. To this purpose, the feasibility of the production of Lignin-containing micro and nanofibrillated cellulose (L-MNFC) from this new lignocellulosic feedstock has been tested. A combinative process including SteamEx as a pre-treatment has been used to examine the impact of the explosive decompression on the fiber's morphology (optical microscopy, Morfi, AFM, turbidity and nanosized fraction) and the chemical composition. L-MNFCs gels has been produced and their quality index have been calculated. Nanopapers were also produced and tested.

\section{Materials And Methods}

\subsection{Materials:}

Eucalyptus globulus barks (EB) used in this work were provided by Unidad de Desarollo Tecnológico (UDT) located in Coronel, Biobio, Chile. They were defibered, dried and dust was removed. Sodium hydroxide used for the pulping was purchased from VWR chemicals (Czech Republic).

\subsection{L-MNFC Preparation:}

EB were soaked, during one night at room temperature, in water (WS for water swelling) or soda solution (SS for soda swelling) (w:W $=1: 100)$ to allow the fibers to swell and facilitate the penetration of chemicals during pulping.

SteamEx has been tested to study the effect of this pre-treatment on the production process. For this purpose, the treatment was Loading [MathJax]/jax/output/CommonHTML/jax.js ratus. The equivalent of $100 \mathrm{~g}$ of barks was impregnated in $200 \mathrm{~mL}$ of $\mathrm{NaOH}$ solution 
( $20 \%$ wt.) during one night. Barks were heated to reach $200^{\circ} \mathrm{C}$ by injecting vapor steam in a pressure reactor ( 20 bar) and heating was maintained during 8 minutes. A sudden decompression ejects barks to the explosion tank. The obtained exploded material was filtered and washed on a $40 \mu \mathrm{m}$ mesh.

In order to get a reference, bark pulping was also performed by conventional soda cooking (SC) in electrically-heated rotating autoclaves. The equivalent of $100 \mathrm{~g}$ of dry barks and a sodium hydroxide solution (20\% wt.) were placed in the autoclave (liquid/solid ratio $=6$ ). The autoclave was hermetically closed and heated while rotating to reach $170^{\circ} \mathrm{C}$. This temperature was maintained during 60 minutes. Autoclave was then cooled and the pulp was filtered and washed on a $40 \mu \mathrm{m}$ mesh.

The equivalent of $30 \mathrm{~g}$ dry pulp from alkaline conventional cooking or SteamEx was then refined using a PFI mill until a drainage index of $70^{\circ} \mathrm{SR}$ (Schopper Riegler degree). Refining was accomplished until 6500-7500 and 8500 revolutions of the PFI mill disk for fibers produced by conventional cooking and SteamEx, respectively.

A $2 \%$ suspension of refined fibers was then grinded using a Masuko grinder (Model MKZA6-2, Disk model MKG-C 80, Masuko Sangyo Co., Ltd, Japan) as following: 10 passes at 0 (750 rpm), 10 passes at -5 (1200 rpm), 15 passes at -10 (1500 rpm), 5 passes at $-15(1700 \mathrm{rpm}), 2$ passes at $-20(1700 \mathrm{rpm})$. The whole process is summarized in figure 1.

Figure 1: Schematic of the L-MNFC production process used in our study.

\subsection{Characterizations:}

Measurements in this part were at least triplicated except for soxhlet extraction and turbidity (1 and 10 measurements, respectively).

\subsubsection{MorFi NEO:}

MorFi NEO is an analyzer of fibers morphology. This technology is based on image analysis of a fiber suspension flowing through a measuring cell. An optical system acquires images, which are processed by a computer. In this work, MorFi NEO was used to determine the fiber length, fiber width and the percentage of fine elements of the suspensions obtained after refining and after Masuko grinding. Measurement time was fixed to 5 minutes and the adopted procedure considers a fiber as an element of length higher than $200 \mu \mathrm{m}$ and fine elements as elements of length less than $200 \mu \mathrm{m}$. For this purpose, different suspensions were prepared by dispersing $0.3 \mathrm{~g}$ of fibers in $1 \mathrm{~L}$ of water.

\subsubsection{Macrosized fraction:}

L-MNFC suspensions were diluted to $0.1 \%$ wt. in deionized water then stirred by ultraturax (IKA®T-25) on speed 5 for 10 minutes. Images of the suspension were taken by a camera placed on an optical microscope (Zeiss Axio Vert.A1, Germany). Images were analyzed by ImageJ to calculate average size of particles.

\subsubsection{Nanosized fraction (NF):}

L-MNFC suspensions were diluted to $0.02 \%$ wt. and stirred by ultraturrax (IKA®T-25) on speed 5 for 6 minutes. $100 \mathrm{~g}$ of suspension were centrifugated for 15 minutes at $4^{\circ} \mathrm{C}$ (velocity $\left.=1000 \mathrm{~g}\right)$. To calculate NF (1), concentrations before $(\mathrm{Cb})$ and after $(\mathrm{Ca})$ centrifugation (in the supernatant phase) were measured:

$$
N f=100 \times \frac{C a}{C b}
$$

\subsubsection{AFM:}

L-MNFC were observed using a BioScope Resolve atomic force microscope (Bruker) in Peak Force Tapping mode using SNL-C tips. For each sample, images were obtained on three different areas. L-MNFC suspensions were diluted to ( $10^{-5} \%$ wt.) in deionized water. $200 \mu \mathrm{l}$ of each suspension were deposited on freshly cleaved mica substrates and let to dry overnight at $30^{\circ} \mathrm{C}$ before imaging.

\subsubsection{Turbidity:}

Loading [MathJax]/jax/output/CommonHTML/jax.js 
The turbidity of L-MNFC suspensions (diluted to $0.1 \%$ wt. and stirred with ultraturrax) was measured with a turbidimeter (Aqualytic, AL-250, wave-length $860 \mathrm{~nm}$ ). This test is based on the determination of the scattered light at an angle of $90^{\circ}$ to the incident light; values are directly linked to the shape, size, concentration and refractive index of the suspended matter.

\subsubsection{Physical and mechanical properties of nanopapers}

Nanopapers were prepared with a handsheet former (Rapid Kothen). The equivalent of $2 \mathrm{~g}$ of dry L-MNFC was diluted to $0.5 \%$ in deionized water. The suspension was filtered on a $1 \mu \mathrm{m}$ nylon sieve under vacuum to remove water. The sheet was dried under vacuum at $85^{\circ} \mathrm{C}$ between two nylon sieves for $12 \mathrm{~min}$. Nanopapers were stored for at least 48 hours in a conditioned room at $23^{\circ} \mathrm{C}$ and $50 \% \mathrm{RH}$ before characterization.

Tensile properties were measured with a vertical extensometer (Instron 5965), following the standard NF Q03-004. Tensile tests were performed at $10 \mathrm{~mm} / \mathrm{min}$. The dimensions of the samples were $10 \mathrm{~cm}$ for the length and $15 \mathrm{~mm}$ for the width. The porosity $(P)$ was calculated as following, considering that nanopaper is constituted of cellulose only:

$$
P=100 \times\left(1-\frac{\rho \text { sample }}{\text { ocellulose }}\right)
$$

Where $\rho$ sample is the density $(\mathrm{g} / \mathrm{cm} 3)$ of the nanopaper and $\rho$ celluloseisequalto $1,5 \mathrm{~g} / \mathrm{cm} 3$.

\subsubsection{Quality index:}

In a previous work, Desmaisons et al. 2017 developed an index that can be used as a quality control for MNFCs at the lab scale or industrial scale. This quality index was calculated according to the simplified formula:

$$
Q I=0.30 x_{1}+\left(-0.03 x_{2}\right)-0.071 x_{3}^{2}+2.54 x_{3}-5.35 \ln x_{7}+59.9
$$

with $\mathrm{x}_{1}$ representing the nanosized fraction (\%), $\mathrm{x}_{2}$ the turbidity (NTU), $\mathrm{x}_{3}$ the Young's modulus (GPa) and $\mathrm{x}_{7}$ the macrosized fraction $\left(\mu \mathrm{m}^{2}\right)$.

\subsubsection{Chemical composition:}

Extraction of approximately $4 \mathrm{~g}$ of raw material or pulps was performed in a Soxhlet apparatus with a toluene/ethanol mixture (2/1 $\mathrm{v} / \mathrm{v}$ ) under reflux, for $8 \mathrm{~h}$. The contents of extractives were determined from the mass of the solid residue after drying at $105^{\circ} \mathrm{C}$, and reported as percent of that of the original sample.

In order to remove tannins and other polyphenols, alkaline lixiviation with $1 \% \mathrm{wt}$. $\mathrm{NaOH}$ was carried out in a stirred glass reactor under reflux using $1.0 \mathrm{~g}$ of the extractive-free material with a $1: 50$ solid: liquid ratio, at $100^{\circ} \mathrm{C}$ for $1 \mathrm{~h}$.

Klason lignin was determined on the extracted materials following an adapted method from National Renewable Energy Laboratory (NREL). Sulphuric acid $\left(72 \%, 1.5 \mathrm{ml}\right.$ ) was added to $0.175 \mathrm{~g}$ of the sample, and the mixture was placed in a water bath at $30^{\circ} \mathrm{C}$ for 1 h. Then, $42 \mathrm{~mL}$ of deionized water were added and the sample was hydrolyzed for $1 \mathrm{~h}$ at $120^{\circ} \mathrm{C}$. The sample was vacuum filtered through a crucible and washed with ultrapure water until obtaining $100 \mathrm{~mL}$ of filtrate. Klason lignin was determined from the mass of the solid residue after drying at $105^{\circ} \mathrm{C}$. The monomer sugar content in liquid fraction was analyzed using high-performance anion-exchange chromatography with pulsed amperometric detection (HPAEC-PAD) (ICS-3000 Dionex).

\subsubsection{Infrared spectroscopy:}

Fourier Transform Infrared (IR) spectra in Attenuated Total Reflexion mode (ATR) were recorded between 4000 and $700 \mathrm{~cm}^{1}$ on a Bruker Vertex 70v spectrometer equipped with a $\mathrm{KBr}$ beam splitter and a deuterated triglycine sulphate (DTGS) thermal detector. The resolution of the single beam spectra was $4 \mathrm{~cm}^{1}$. A single-reflection diamond ATR accessory (Platinum ATR diamond, Bruker) was used for acquiring the spectra. The incidence angle was $45^{\circ}$ and the refraction index of the crystal was 2.4. The number of bidirectional double-sided interferogram scans was 200 , which corresponds to a two-minute accumulation. All the interferograms were Fourier processed using the Mertz phase correction mode and a Blackman-Harris three-term apodization function. No ATR corrention was nerformed IR- $\Delta T R$ cnectra are shown with an absorbance scale corresponding to $\log \left(R_{\text {reference }} / R_{\text {sample }}\right)$, where $R$ is Loading [MathJax]/jax/output/CommonHTML/jax.js 
the internal reflectance of the device. Recording of the spectra, data storage and data processing were performed using the Bruker OPUS 7.8 software. The measurements were performed at $21 \pm 1^{\circ} \mathrm{C}$ in an air-conditioned room. The obtained fibers after alkaline SteamEx and conventional cooking in rotating autoclaves were laid on the ATR crystal and gently pushed on it to ensure a good contact between fibers and the diamond crystal. Water vapor subtraction was performed when necessary. The base line was corrected at $3600,2750,1800$ and $800 \mathrm{~cm}^{1}$. The spectra were normalized to one from region $1800-800 \mathrm{~cm}^{-1}$.

\section{Results And Discussion}

The effect of SteamEx on the morphology and composition of lignocellulosic fibers has been extensively described in the literature. In a SteamEx treatment, the biomass is first impregnated and then treated with saturated steam at high pressure for a short period (only few minutes). During the cooking step, a hydrolytic breakdown of the lignocellulosic complex occurs impacting primarily noncellulosic polymers (hemicelluloses and lignin). The second step consists of a quick depressurization causing water expansion and physical degradation of the fibrous material. As a result, this process leads to a significant modification of the cell wall structure, degrading the cell middle lamella and allowing the extraction of cellulosic fibers from biomass. One of the most studied applications of SteamEx is the production of a cellulose-rich residue bearing a higher enzyme accessibility for bioethanol production. In this study, SteamEx has been experimented as a pre-treatment s for L-MNFC gel production. Alkaline conditions have been used to promote the defibration by removing lignin cement. In order to identify the impact of SteamEx on the fibers, a conventional soda cooking performed in electrically-heated rotating autoclaves without explosive decompression step was experimented.

\subsection{Pulping yield and chemical composition:}

Table 1 reports the pre-treatment and pulping conditions as well as the yield and the chemical composition of the different produced pulps.

It appears that non-treated EB contains $15.1 \%$ and $19.9 \pm 1.4 \%$ toluene-EtOH and $1 \% \mathrm{NaOH}$ extractives, respectively. The lignin content is equal to $14.5 \pm 0.5 \%$. Cellulose and hemicellulose content are $34.03 \pm 0.3$ and $14.7 \pm 0.0$, respectively.

The pulping yield after conventional pulping was $58 \%$ wt. and $52 \%$ wt. for fibers soaked in water and $1 \%$ wt. soda, respectively. The data in Table 1 also shows that Toluene-EtOH and 1\% NaOH extractives content decreased to about $8 \%$ and $12 \%$. After pulping, hemicellulose and lignin contents are close to $9 \%$ and $6.5 \%$. Meanwhile, obtained pulps contains about $50 \%$ of cellulose.

Chemical composition was also analyzed after alkaline SteamEx. Data in Table 1 shows that pulps were obtained with a yield of 40-44 \% wt. Toluene-EtOH and $1 \% \mathrm{NaOH}$ extractives content are close to $8 \%$ and $10 \%$. Hemicellulose and lignin contents decreased to about $11 \%$ and $9.0 \%$. Meanwhile cellulose content is $58.0-60.0 \%$.

Results thus show that alkaline SteamEx allowed the isolation of fibers with comparable chemical composition with those isolated with conventional soda cooking method in autoclaves (SC). The advantages of SteamEx is that the cooking time is lower compared to SC (8 min and $60 \mathrm{~min}$, respectively). Both approaches lead to hemicellulose hydrolysis and partial delignification. Nevertheless, in the tested experimental conditions, the yield is higher for conventional pulping even if delignification is greater. This observation is in accordance with the work of Lavoie et al. 2010 showing that the yield of kraft pulping was higher than that of SteamEx (34\% and $30 \%$ respectively).

NTEB, SC and SteamEx fibers were analyzed using IR-ATR to examine the changes in their chemical composition before and after the treatments (Figure 2). The bands at $1750 \mathrm{~cm}^{-1}$ (Kaushik and Singh 2011), present in the spectrum of NTEB, is assigned to the vibrations of the carboxyl and acetyl groups of hemicelluloses. The absence of this band in the SC and SteamEx fibers is in accordance with the low hemicelluloses content previously observed (Table 1) and can also be justified by saponification reactions of acetyl moieties. Spectra also show a drastic decrease in intensity of the bands at $1600 \mathrm{~cm}^{-1}$ and at $1510 \mathrm{~cm}^{-1}$, and attributed to the $\mathrm{C}=\mathrm{C}$ stretching from the aromatic Guaiacyl (G), Syringyl (S) ring of the lignin, respectively (Carrillo et al., 2018). A decrease of the band at $1260 \mathrm{~cm}^{1}$ (Kaushik and Singh 2011) assigned to C-O stretching from lignin and hemicelluloses is also observed. All these observations confirm the hemicelluloses hydrolysis and the delignification during the conventional pulping and the SteamEx. In

Loading [MathJax]/jax/output/CommonHTML/jax.js and C-O stretching vibrations absorb, the general feature of the massif resembles to 
those of commercial cellulose (Richard et al., 2014). In addition, the anomeric band at $896 \mathrm{~cm}^{1}$, specific for $\beta$-linkages in cellulose, is clearly resolved in the spectra of the treated samples.

Table 1

pulping conditions, yield and chemical composition of fibers obtained by alkaline SteamEx and conventional cooking in rotating autoclaves (values are given in wt\% based on $100 \mathrm{~g}$ of pulp).

\begin{tabular}{|c|c|c|c|c|c|c|c|c|c|}
\hline \multirow[t]{2}{*}{ Sample } & \multirow[t]{2}{*}{ Pretreatment } & \multirow{2}{*}{$\begin{array}{l}\text { Temperature } \\
\left({ }^{\circ} \mathrm{C}\right)\end{array}$} & \multirow{2}{*}{$\begin{array}{l}\text { Time } \\
(\min )\end{array}$} & \multirow{2}{*}{$\begin{array}{l}\text { Yield } \\
\text { (\%) }\end{array}$} & \multicolumn{5}{|c|}{ Chemical composition } \\
\hline & & & & & $\begin{array}{l}\text { Toluene- } \\
\text { EtOH } \\
\text { extractives }\end{array}$ & $\begin{array}{l}1 \% \mathrm{NaOH} \\
\text { extractives }\end{array}$ & Lignin & Hemicelluloses & Cellulose \\
\hline EB & No treatment & & & & 15,1 & $19,9 \pm 1,4$ & $\begin{array}{l}14,5 \pm \\
0,5\end{array}$ & $14,7 \pm 0,0$ & $\begin{array}{l}34,3 \pm \\
0,3\end{array}$ \\
\hline WS-SC & $\begin{array}{l}\text { Conventional } \\
\text { soda pulping }\end{array}$ & 170 & 60 & 58 & 8,0 & $12,9 \pm 0,5$ & $\begin{array}{l}6,8 \pm \\
0,4\end{array}$ & $8,2 \pm 1,7$ & $\begin{array}{l}49,5 \pm \\
5,1\end{array}$ \\
\hline SS-SC & & & & 52 & 8,4 & $11,7 \pm 0,5$ & $\begin{array}{l}6,3 \pm \\
0,6\end{array}$ & $10,9 \pm 1,2$ & $\begin{array}{l}52,2 \pm \\
3,4\end{array}$ \\
\hline $\begin{array}{l}\text { WS- } \\
\text { SteamEx }\end{array}$ & SteamEx & 200 & 8 & 44 & 8,1 & $11,7 \pm 0,5$ & $\begin{array}{l}8,6 \pm \\
0,4\end{array}$ & $10,3 \pm 0,4$ & $\begin{array}{l}58,0 \pm \\
1,3\end{array}$ \\
\hline $\begin{array}{l}\text { SS- } \\
\text { SteamEx }\end{array}$ & & & & 40 & 8,2 & $8,0 \pm 0,6$ & $\begin{array}{l}9.0 \pm \\
0,4\end{array}$ & $11,8 \pm 0,8$ & $\begin{array}{l}60.0 \pm \\
4,3\end{array}$ \\
\hline
\end{tabular}

\subsection{Refining:}

Figure 3 shows the evolution of the Schopper Riegler degree of the obtained pulps as a function of the number of revolutions of the PFI mill.

We can observe from Fig. 3 that the four pulps do not display the same refining behavior. WS-SC and SS-SC pulps (conventional cooking in autoclaves) were refined more easily than SteamEx pulps, a Schopper Riegler degree of 70 being reached after $\approx 6000$ revolutions and $\approx 8000$ revolutions respectively. These different behaviors can be explained, at least partially, by the slight difference in lignin content: lignin makes the separation of hemicelluloses and cellulose in the lignocellulosic matrix more difficult (Tuzzin et al., 2016), limits the swelling of fibers and thus negatively impacts the refining ability of the pulps.

\subsection{Morphological properties:}

Table 2 shows the data obtained from MorFi NEO analyzer. Before grinding, the refined pulps exhibit important morphological differences: compared to SC fibers, SteamEx fibers are shorter $(\approx 560 \mu \mathrm{m}$ and $\approx 400 \mu \mathrm{m}$, respectively) with higher fine elements contents $(\approx 65 \%$ and $\approx 85 \%$, in length respectively). A higher number of fine elements (length $<200 \mu \mathrm{m})$ was also detected 5.3 $6.3 \times 10^{4}$ and $7.3-6.3 \times 10^{4}$ for SC and SteamEx, respectively. These results prove a most intense degradation of the fibers with a production of shorter fragments for the SteamEx process. The mean total length was calculated for the refined samples. Results show that the total length is $\approx 204-222 \mu \mathrm{m}$ and $\approx 77-90 \mu \mathrm{m}$ for SC and SteamEx, respectively which reveals that the remaining fibers after SteamEx are 2.5 times shorter than after SC. On the other hand, Morfi shows a greater width of the SteamEx refined fibers $(\approx 19.5 \mu \mathrm{m}$ and $\approx 22.5 \mu \mathrm{m}$, for SC and SteamEx respectively). This is due to the higher content of lignin for SteamEx (see Table 1). This higher lignin content can lead to a lower separation of fibers.

Regarding now the L-MNFC gels, it can also be seen that grinding step has a levelling effect on the morphological properties of the fibers produced but SteamEx residual fibers are still shorter ( $\approx 300 \mu \mathrm{m}$ compared to $360 \mu \mathrm{m}$ for SC). As expected, the number of fibers (length $>200 \mu \mathrm{m}$ ) detected by MorFi decreases from $\approx 12.2-13,5 \times 10^{3}$ in the refined pulps to $\approx 0.6-2.0 \times 10^{3}$ in the gels because of the grinding process which enhances the fragmentation of fibers into finer elements. The fine element content reaches $98 \%$ (in length) and SteamEx gels exhibit the highest number of fine elements (21.7- $24.9 \times 10^{5}$ ) compared to SC gels (5.27 - 5.85 $\left.x 10^{5}\right)$. Finally, the difference in total mean length is also observed in the gels produced after grinding $(\approx 33-38 \mu \mathrm{m}$ and $\approx 26-31$ Loading [MathJax]/jax/output/CommonHTML/jax.js e observations are in accordance with previously reported works : (Luo et al., 2018) 
found that length and fine content of wind mill palm fibres were highly affected by SteamEx. (Sauvageon et al., 2018) reported that alkali SteamEx performed from hemp fibres at high severity produced short and damaged fibres.

Table 2

MorFi Analyzer results for refined pulps, and L-MNFC gels. Key: WS, water swelling; SS, soda swelling; SC, conventional soda cooking in autoclaves.

\begin{tabular}{|c|c|c|c|c|c|c|c|}
\hline $\begin{array}{l}\text { Mechanical } \\
\text { treatment }\end{array}$ & Sample & $\begin{array}{l}\text { Fibers number } \\
\text { (fibers/g) }\end{array}$ & $\begin{array}{l}\text { Length } \\
(\mu \mathrm{m})\end{array}$ & $\begin{array}{l}\text { Width } \\
(\mu \mathrm{m})\end{array}$ & $\begin{array}{l}\text { Fines } \\
\text { number } \\
\text { (fines/g) }\end{array}$ & $\begin{array}{l}\text { Fines content } \\
(\%)\end{array}$ & $\begin{array}{l}\text { Fines length } \\
(\mu \mathrm{m})\end{array}$ \\
\hline \multirow[t]{4}{*}{ Refining } & WS-SC & $13.05 \times 10^{3}$ & $558 \pm 2$ & $\begin{array}{l}19.8 \pm \\
0.1\end{array}$ & $6.26 \times 10^{5}$ & 67 & 31 \\
\hline & SS-SC & $12.74 \times 10^{3}$ & $565 \pm 2$ & $\begin{array}{l}19.4 \pm \\
0.1\end{array}$ & $5.26 \times 10^{5}$ & 64 & 32 \\
\hline & $\begin{array}{l}\text { WS- } \\
\text { SteamEx }\end{array}$ & $13.51 \times 10^{3}$ & $399 \pm 1$ & $\begin{array}{l}21.6 \pm \\
0.2\end{array}$ & $6.88 \times 10^{5}$ & 84 & 32 \\
\hline & $\begin{array}{l}\text { SS- } \\
\text { SteamEx }\end{array}$ & $12.27 \times 10^{3}$ & $400 \pm 2$ & $\begin{array}{l}23.7 \pm \\
0.2\end{array}$ & $7.33 \times 10^{5}$ & 88 & 31 \\
\hline \multirow[t]{4}{*}{ Masuko grinding } & WS-SC & $0.61 \times 10^{3}$ & $360 \pm 3$ & $\begin{array}{l}23,6 \pm \\
0.3\end{array}$ & $5.27 \times 10^{5}$ & 98 & 26 \\
\hline & SS-SC & $0.98 \times 10^{3}$ & $355 \pm 3$ & $\begin{array}{l}23,0 \pm \\
0.3\end{array}$ & $5.85 \times 10^{5}$ & 97 & 28 \\
\hline & $\begin{array}{l}\text { WS- } \\
\text { SteamEx }\end{array}$ & $2.76 \times 10^{3}$ & $307 \pm 2$ & $\begin{array}{l}21,7 \pm \\
0.5\end{array}$ & $24.9 \times 10^{5}$ & 99 & 27 \\
\hline & $\begin{array}{l}\text { SS- } \\
\text { SteamEx }\end{array}$ & $7.58 \times 10^{3}$ & $293 \pm 4$ & $\begin{array}{l}22,0 \pm \\
0.6\end{array}$ & $21.7 \times 10^{5}$ & 99 & 25 \\
\hline
\end{tabular}

From samples shown in AFM images given (Fig. 4a, b and d) present a web like morphology with some aggregates. The height of LMNFCs, calculated from AFM Images, varies between 5 and $100 \mathrm{~nm}$ and no significant difference was observed between SC and SteamEx samples. For the SteamEx sample, dispersed globular particles are clearly visible (Fig. 4d). Based on literature data, they are most probably composed of lignin (Vignon et al. 1995; Ehman et al. 2020; Yuan et al. 2021). In fact, during SteamEx, lignin is depolymerized through aryl-ether scission producing small lignin fragments. The temperature of the SteamEx treatment being higher than that of the degraded lignin, the lignin becomes mobile and migrates within the biomass sample. Due to its hydrophobic nature, lignin coalesces into spheres to minimize its contact surface with water. This lignin translocation has been observed by microscopic techniques in the form of droplets on the fiber surface.

The determination of the macrosized fraction was not adapted for the L-MNFC suspensions obtained in our study. because of the size distribution of the samples which was an obstacle for this measurement. The calculated average size of microparticles was certainly overestimated. However, there was no significant difference between the mean values $(\approx 50 \mu \mathrm{m})$ calculated for the different suspensions.

Figure 5 shows the turbidity and the nanosized fraction of the L-MNFC suspensions. According to Nuopponen et al. 2013, with respect to turbidity, the lower the turbidity value, the more nano-sized material the sample should contain. The results obtained agree with those of the nanometric fraction: SS-SteamEx has the highest nanometric fraction and the lowest turbidity and the WSSteamEx sample, with the lowest nanometric fraction, has the highest turbidity. However, the differences between the samples are not really significant.

\subsection{Nanopapers}

Nanopapers have been prepared from L-MNFC gels produced in this study. Table 3 gives their physical and mechanical properties All the prepared nanopapers have comparable Young's modulus and the values, comprised between 8.4 and $9.5 \mathrm{GPa}$ are quite Loading [MathJax]/jax/output/CommonHTML/jax.js nin in L-MNFC on the mechanical properties of nanopapers is still debated. This effect 
depends on the lignin content and the production process (Rojo et al., 2015; Albornoz-Palma et al., 2020). In our work, we can observe that lignin content has no visible effect on the Young's modulus. Meanwhile, in accordance with previous papers (Fukuzumi et al. 2013 and Meng et al. 2017), Young's moduli of the nanopapers given in Table 2 are in good agreement with the length. SS-SC gels containing the particles $(\approx 38 \mu \mathrm{m})$ produced nanopapers with the highest Young's modulus $(9.74 \mathrm{GPa})$. On the other side SSSteamEx having the shortest fibers $(\approx 26 \mu \mathrm{m})$, have the nanopapers with the lowest young's modulus $(\approx 8,47 \mathrm{GPa})$.

Good values of Young's modulus must be related to the density of the nanopapers which are close to $1150 \mathrm{Kg} / \mathrm{m}^{3}$. The density is slightly higher in the case of SteamEx nanopapers. Nanopaper porosity is comprised between 20 (SteamEx) and $26 \%$ (SC). The presence of lignin nanoparticles in SteamEx L-MNFC could impact the nanopaper density. In accordance with Bian et al. 2018 higher lignin content of SteamEx fibers could allow their more effective compaction during the paper formation leading to a higher paper density and a lower porosity. In our study, and even if we consider L-MNFCs instead of fibers, the presence of lignin nanoparticles observed by AFM could also have an effect by filling the voids within the cellulose fibrils, thus impacting nanopaper density. Moreover, analyses of the morphological properties (MorFi) showed that the number of fine elements is higher for SteamEx L-MNFC gels. Even if this measurement is not carried out at the nanoscale, the probable presence of more fine elements in these gels could lead to a higher density.

Table 3

Mechanical and physical properties of nanopapers prepared from L-MNFC gels.

\begin{tabular}{|llllll|}
\hline M/NFC suspension & Young's modulus $(\mathrm{GPa})$ & Thickness $(\mu \mathrm{m})$ & Grammage $(\mathrm{g} / \mathrm{m} 2)$ & Density $(\mathrm{Kg} / \mathrm{m} 3)$ & Porosity $(\%)$ \\
\hline WS-SC & $8,67 \pm 0,09$ & 58,67 & 65,21 & 1111 & 26 \\
\hline SS-SC & $9,45 \pm 0,05$ & 58,00 & 64,34 & 1109 & 26 \\
\hline WS-SteamEx & $8,85 \pm 0,25$ & 58,33 & 71,30 & 1222 & 19 \\
\hline SS-SteamEx & $8,42 \pm 0,08$ & 55,33 & 65,38 & 1182 & 21 \\
\hline
\end{tabular}

\subsection{Quality index}

Figure 6 shows the quality index of the L-MNFC gels.

Quality indexes are quite similar for all the produced gels: it varies between 54-56 and 52-57 for SC and SteamEx, respectively. The lower value for the WS-SteamEx suspension is due to the highest turbidity value measured for this sample. Values obtained in this work are comparable to values of enzymatic commercial MNFCs (quality index $\approx 60$ ) (Desmaisons et al., 2017).

\section{Conclusion}

In this work, lignin-containing micro- and nano-fibrillated cellulose (L-MNFCs) were produced from Eucalyptus barks through a sequential process using steam explosion as pre-treatment. Pulps were also obtained using conventional soda cooking in rotating autoclaves to compare the different production processes. In the tested experimental conditions, the obtained results showed that the use of alkaline SteamEx allows to obtain pulps with comparable chemical composition to conventional pulping methods but with a significantly lower cooking time. L-MNFC exhibit web like morphology with a width of 5-100 nm. AFM images showed that SteamEx L-MNFCs also contain lignin nanoparticles expelled during the explosive decompression. These lignin nanoparticles, as well as the higher number of fine elements, probably explain the higher density of the SteamEx nanopapers. These results thus show the interest of using alkaline SteamEx pre-treatment as an alternative way to produce L-MNFCs comparable to L-MNFCs obtained by conventional cooking, with respect to the quality index.

\section{Declarations}

\section{Authors contributions}

Conceptualization: Nicolas BROSSE, Evelyne MAURET and Saad NADER; Methodology and investigation: Saad NADER, Malek Loading [MathJax]/jax/output/CommonHTML/jax.js nne QUILES and Sofiane EL KIRAT CHATEL; Original draft preparation: Saad NADER; 
Review and editing: Nicolas BROSSE, Evelyne MAURET and Saad NADER; Supervision: Nicolas BROSSE and Evelyne MAURET; Funding acquisition: Nicolas BROSSE, Evelyne MAURET and Cecilia FUENTEALBA

All authors have read and agreed to the published version of the manuscript.

\section{Acknowledgements}

The authors gratefully acknowledge the financial support of Labex Tec21 and LAbex Arbre for the thesis funding. This work was also supported by the Franco-Chilean EcosSud Collaborative Program C18E05, ANID PIA/Apoyo CCTE AFB170007 of Universidad de Concepción. We thank the Spectroscopy and Microscopy of interfaces Service Facility (SMI) of LCPME where the IR-ATR and AFM measurements were performed (Université de Lorraine-CNRS- http://www.lcpme.cnrs-nancy.fr; LCPME, UMR7564, 405 rue de Vandoeuvre 54600, France).

\section{References}

1. Abraham, E., B. Deepa, L.A. Pothan, M. Jacob, S. Thomas, U. Cvelbar, et R. Anandjiwala. 2011. «Extraction of Nanocellulose Fibrils from Lignocellulosic Fibres: A Novel Approach ». Carbohydrate Polymers 86 (4): 1468-75. https://doi.org/10.1016/j.carbpol.2011.06.034.

2. Ahola, Susanna. 2008. "Cellulose Nanofibrils-Adsorption with Poly(Amideamine) Epichlorohydrin Studied by QCM-D and Application as a Paper Strength Additive », 12.

3. Albornoz-Palma, Gregory, Daniel Ching, Oscar Valerio, Regis Teixeira Mendonça, et Miguel Pereira. 2020. « Effect of Lignin and Hemicellulose on the Properties of Lignocellulose Nanofibril Suspensions ». Cellulose 27 (18): 10631-47. https://doi.org/10.1007/s10570-020-03304-5.

4. Bäckström, M., S. Bolivar, et J. Paltakari. 2012. «Effect of Ionic Form on Fibrillation and the Development of the Fibre Network Strength during the Refining of the Kraft Pulps ». O Papel, nº 7: 57-65.

5. Carrillo, Isabel, Regis Teixeira Mendonça, Mariko Ago, et Orlando J. Rojas. 2018. « Comparative Study of Cellulosic Components Isolated from Different Eucalyptus Species ». Cellulose 25 (2): 1011-29. https://doi.org/10.1007/s10570-0181653-2.

6. Chadni, Morad, Nabil Grimi, Olivier Bals, Isabelle Ziegler-Devin, et Nicolas Brosse. 2019. "Steam Explosion Process for the Selective Extraction of Hemicelluloses Polymers from Spruce Sawdust ». Industrial Crops and Products 141 (décembre): 111757. https://doi.org/10.1016/j.indcrop.2019.111757.

7. Chandra, Richard P., QiuLu Chu, Jinguang Hu, Na Zhong, Mandy Lin, Jin-Suk Lee, et Jack Saddler. 2016. « The Influence of Lignin on Steam Pretreatment and Mechanical Pulping of Poplar to Achieve High Sugar Recovery and Ease of Enzymatic Hydrolysis ». Bioresource Technology 199 (janvier): 135-41. https://doi.org/10.1016/j.biortech.2015.09.019.

8. Cherian, Bibin Mathew, Alcides Lopes Leão, Sivoney Ferreira de Souza, Sabu Thomas, Laly A. Pothan, et M. Kottaisamy. 2010. « Isolation of Nanocellulose from Pineapple Leaf Fibres by Steam Explosion ». Carbohydrate Polymers 81 (3): 720-25. https://doi.org/10.1016/j.carbpol.2010.03.046.

9. Cherian, Bibin Mathew, Laly A. Pothan, Tham Nguyen-Chung, Günter Mennig, M. Kottaisamy, et Sabu Thomas. 2008. « A Novel Method for the Synthesis of Cellulose Nanofibril Whiskers from Banana Fibers and Characterization ». Journal of Agricultural and Food Chemistry 56 (14): 5617-27. https://doi.org/10.1021/jf8003674.

10. Desmaisons, Johanna, Elisa Boutonnet, Martine Rueff, Alain Dufresne, et Julien Bras. 2017. «A New Quality Index for Benchmarking of Different Cellulose Nanofibrils ». Carbohydrate Polymers 174 (octobre): 318-29. https://doi.org/10.1016/j.carbpol.2017.06.032.

11. Dufresne, Alain. 2012. Nanocellulose: From Nature to High Performance Tailored Materials. De Gruyter. https://lib.hpu.edu.vn/handle/123456789/30932.

12. Ehman, N.V., A.F. Lourenço, B.H. McDonagh, M.E. Vallejos, F.E. Felissia, P.J.T. Ferreira, G. Chinga-Carrasco, et M.C. Area. 2020. « Influence of Initial Chemical Composition and Characteristics of Pulps on the Production and Properties of Lignocellulosic Nanofibers ». International Journal of Biological Macromolecules 143 (janvier): 453-61.

httns.//dni ora/10 1016/i iihinmac. 2019.10.165.

Loading [MathJax]/jax/output/CommonHTML/jax.js 
13. Eriksen, Øyvind, Kristin Syverud, et Øyvind Gregersen. 2008. « The Use of Microfibrillated Cellulose Produced from Kraft Pulp as Strength Enhancer in TMP Paper ». Nordic Pulp \& Paper Research Journal 23 (3): 299-304. https://doi.org/10.3183/npprj-200823-03-p299-304.

14. Fuentealba, Cecilia, Juan Montory, Johana Vega, et José Norambuena-Contreras. 2016. New Biobased composite material using bark fibres Eucalyptus.

15. Fukuzumi, Hayaka, Tsuguyuki Saito, et Akira Isogai. 2013. «Influence of TEMPO-Oxidized Cellulose Nanofibril Length on Film Properties ». Carbohydrate Polymers 93 (1): 172-77. https://doi.org/10.1016/j.carbpol.2012.04.069.

16. Gane, Patrick A C, Joachim Schoellkopf, Daniel Gantenbein, et Schenker Oftringen. 2010. « Pohl, Villach (AT). Beat Kübler », 15.

17. Henriksson, M., G. Henriksson, L.A. Berglund, et T. Lindström. 2007. « An Environmentally Friendly Method for Enzyme-Assisted Preparation of Microfibrillated Cellulose (MFC) Nanofibers ». European Polymer Journal 43 (8): 3434-41. https://doi.org/10.1016/j.eurpolymj.2007.05.038.

18. Herrick, F. W., R. L. Casebier, J. K. Hamilton, et K. R. Sandberg. 1983. " Microfibrillated Cellulose: Morphology and Accessibility ». J. Appl. Polym. Sci.: Appl. Polym. Symp.; (United States) 37 (janvier). https://www.osti.gov/biblio/5039044.

19. Ho, Thao Thi Thu, Kentaro Abe, Tanja Zimmermann, et Hiroyuki Yano. 2015. « Nanofibrillation of Pulp Fibers by Twin-Screw Extrusion ». Cellulose 22 (1): 421-33. https://doi.org/10.1007/s10570-014-0518-6.

20. Jacquet, Nicolas, Caroline Vanderghem, Christophe Blecker, et Michel Paquot. 2010. « La steam explosion : application en tant que prétraitement de la matière lignocellulosique». Biotechnol. Agron. Soc. Environ., 6.

21. Kaushik, Anupama, et Mandeep Singh. 2011. «Isolation and Characterization of Cellulose Nanofibrils from Wheat Straw Using Steam Explosion Coupled with High Shear Homogenization ». Carbohydrate Research 346 (1): 76-85. https://doi.org/10.1016/j.carres.2010.10.020.

22. Kessler, R W, U Becker, R Kohler, et B Goth. 1995. « STEAM EXPLOSION OF FLAX Đ A SUPERIOR TECHNIQUE FOR UPGRADING FIBRE VALUE », 13.

23. Klemm, Dieter, Friederike Kramer, Sebastian Moritz, Tom Lindström, Mikael Ankerfors, Derek Gray, et Annie Dorris. 2011. « Nanocelluloses: A New Family of Nature-Based Materials ». Angewandte Chemie International Edition 50 (24): 5438-66. https://doi.org/10.1002/anie.201001273.

24. Lavoie, Jean-Michel, Eva Capek-Menard, Henri Gauvin, et Esteban Chornet. 2010. « Production of Pulp from Salix Viminalis Energy Crops Using the FIRSST Process ». Bioresource Technology 101 (13): 4940-46. https://doi.org/10.1016/j.biortech.2009.09.021.

25. Lavoine, Nathalie. 2012. "Microfibrillated Cellulose - Its Barrier Properties and Applications in Cellulosic Materials: A Review ». Carbohydrate Polymers, 30.

26. Lin, Ning, et Alain Dufresne. 2014. "Surface Chemistry, Morphological Analysis and Properties of Cellulose Nanocrystals with Gradiented Sulfation Degrees ». Nanoscale 6 (10): 5384-93. https://doi.org/10.1039/C3NR06761K.

27. Lindström, Tom, Mikael Ankerfors, et Christian Aulin. 2011. « Nanocellulose Research and Developments at Innventia ». In. http://urn.kb.se/resolve?urn=urn:nbn:se:ri:diva-9473.

28. Luo, Hai, Haiyang Zhang, Lei Yue, Antonio Pizzi, et Xiaoning Lu. 2018. «Effects of Steam Explosion on the Characteristics of Windmill Palm Fiber and Its Application to Fiberboard ». European Journal of Wood and Wood Products 76 (2): 601-9. https://doi.org/10.1007/s00107-017-1259-7.

29. Meng, Qinghua, Bo Li, Teng Li, et Xi-Qiao Feng. 2017. "A Multiscale Crack-Bridging Model of Cellulose Nanopaper ». Journal of the Mechanics and Physics of Solids 103 (juin): 22-39. https://doi.org/10.1016/j.jmps.2017.03.004.

30. Miranda, Isabel, Jorge Gominho, et Helena Pereira. 2012. « INCORPORATION OF BARK AND TOPS IN EUCALYPTUS GLOBULUS WOOD PULPING », 13.

31. Missoum, Karim, Mohamed Belgacem, et Julien Bras. 2013. « Nanofibrillated Cellulose Surface Modification: A Review ». Materials 6 (5): 1745-66. https://doi.org/10.3390/ma6051745.

32. Nechyporchuk, Oleksandr. 2016. «Production of Cellulose Nanofibrils: A Review of Recent Advances ». Industrial Crops and Products, 24.

33. Nuopponen, Markus, Taru Päiväläinen, Antti Laukkanen, et Jouni Paltakari. 2013. Method for manufacturing nanofibrillated Loading [MathJax]/jax/output/CommonHTML/jax.js per manufacturing or in nanofibrillated cellulose composites. United States 
US20130000855A1, filed 5 novembre 2010, et issued 3 janvier 2013.

https://patents.google.com/patent/US20130000855A1/en.

34. Obame, Sebastien Ngwa, Isabelle Ziegler-Devin, Rodrigue Safou-Tchima, et Nicolas Brosse. 2019. « Homolytic and Heterolytic Cleavage of $\beta$-Ether Linkages in Hardwood Lignin by Steam Explosion ». Journal of Agricultural and Food Chemistry 67 (21): 5989-96. https://doi.org/10.1021/acs.jafc.9b01744.

35. Park, Chan-Woo, Song-Yi Han, Hyun-Woo Namgung, Pureun-narae Seo, Sun-Young Lee, et Seung-Hwan Lee. 2017. « Preparation and Characterization of Cellulose Nanofibrils with Varying Chemical Compositions ». BioResources 12 (3): 5031-44. https://doi.org/10.15376/biores.12.3.5031-5044.

36. Richard, Béatrice, Fabienne Quilès, Cédric Carteret, et Oliver Brendel. 2014. «Infrared Spectroscopy and Multivariate Analysis to Appraise a-Cellulose Extracted from Wood for Stable Carbon Isotope Measurements ». Chemical Geology 381 (août): 168-79. https://doi.org/10.1016/j.chemgeo.2014.05.010.

37. Rojo, Ester, Maria Soledad Peresin, William W. Sampson, Ingrid C. Hoeger, Jari Vartiainen, Janne Laine, et Orlando J. Rojas. 2015. « Comprehensive Elucidation of the Effect of Residual Lignin on the Physical, Barrier, Mechanical and Surface Properties of Nanocellulose Films ». Green Chemistry 17 (3): 1853-66. https://doi.org/10.1039/C4GC02398F.

38. Romaní, Aloia, Antonio Larramendi, Remedios Yáñez, Ángeles Cancela, Ángel Sánchez, José A. Teixeira, et Lucília Domingues. 2019. «Valorization of Eucalyptus Nitens Bark by Organosolv Pretreatment for the Production of Advanced Biofuels ». Industrial Crops and Products 132 (juin): 327-35. https://doi.org/10.1016/j.indcrop.2019.02.040.

39. Sartori, Caroline, Graciene da Silva Mota, Joana Ferreira, Isabel Miranda, Fábio Akira Mori, et Helena Pereira. 2016. « Chemical Characterization of the Bark of Eucalyptus Urophylla Hybrids in View of Their Valorization in Biorefineries ». Holzforschung 70 (9): 819-28. https://doi.org/10.1515/hf-2015-0258.

40. Sauvageon, Thibaud, Jean-Michel Lavoie, César Segovia, et Nicolas Brosse. 2018. « Toward the Cottonization of Hemp Fibers by Steam Explosion - Part 1: Defibration and Morphological Characterization ». Textile Research Journal 88 (9): 1047-55. https://doi.org/10.1177/0040517517697644.

41. Sehaqui, Houssine. 2011. « High-Porosity Aerogels of High Specific Surface Area Prepared from Nanofibrillated Cellulose (NFC) ». Composites Science and Technology, 7.

42. Siro, Istvan, et David Plackett. 2010. « Microfibrillated Cellulose and New Nanocomposite Materials: A Review », 36.

43. Sun, Ye, et Jiayang Cheng. 2002. « Hydrolysis of Lignocellulosic Materials for Ethanol Production: A Review q ». Bioresource Technology, 11.

44. Sutka, Anna, Silvija Kukle, Janis Gravitis, et Agris Berzins. 2013. "Chemical and Physical Modification of Hemp Fibres by Steam Explosion Technology ». Materials Science and Engineering, 5.

45. Takada, Masatsugu, Richard P. Chandra, et John N. Saddler. 2019. «The Influence of Lignin Migration and Relocation during Steam Pretreatment on the Enzymatic Hydrolysis of Softwood and Corn Stover Biomass Substrates ». Biotechnology and Bioengineering 116 (11): 2864-73. https://doi.org/10.1002/bit.27137.

46. Tuzzin, Glaiton, Marcelo Godinho, Aline Dettmer, et Ademir José Zattera. 2016. « Nanofibrillated Cellulose from Tobacco Industry Wastes ». Carbohydrate Polymers 148 (septembre): 69-77. https://doi.org/10.1016/j.carbpol.2016.04.045.

47. Ullah, Hanif, Hélder A. Santos, et Taous Khan. 2016. « Applications of Bacterial Cellulose in Food, Cosmetics and Drug Delivery ». Cellulose 23 (4): 2291-2314. https://doi.org/10.1007/s10570-016-0986-y.

48. Vignon, M R, C Garcia-Jaldon, et D Dupeyre. 1995. «Steam Explosion of Woody Hemp Ch Nevotte», 10.

49. Wang, Xuan, Xiaoxia Cui, et Liping Zhang. 2012. «Preparation and Characterization of Lignin-Containing Nanofibrillar Cellulose ». Procedia Environmental Sciences 16: 125-30. https://doi.org/10.1016/j.proenv.2012.10.017.

50. Yuan, Tianzhong, Jinsong Zeng, Bin Wang, Zheng Cheng, et Kefu Chen. 2021. « Lignin Containing Cellulose Nanofibers (LCNFs): Lignin Content-Morphology-Rheology Relationships ». Carbohydrate Polymers 254 (février): 117441. https://doi.org/10.1016/j.carbpol.2020.117441.

\section{Figures}




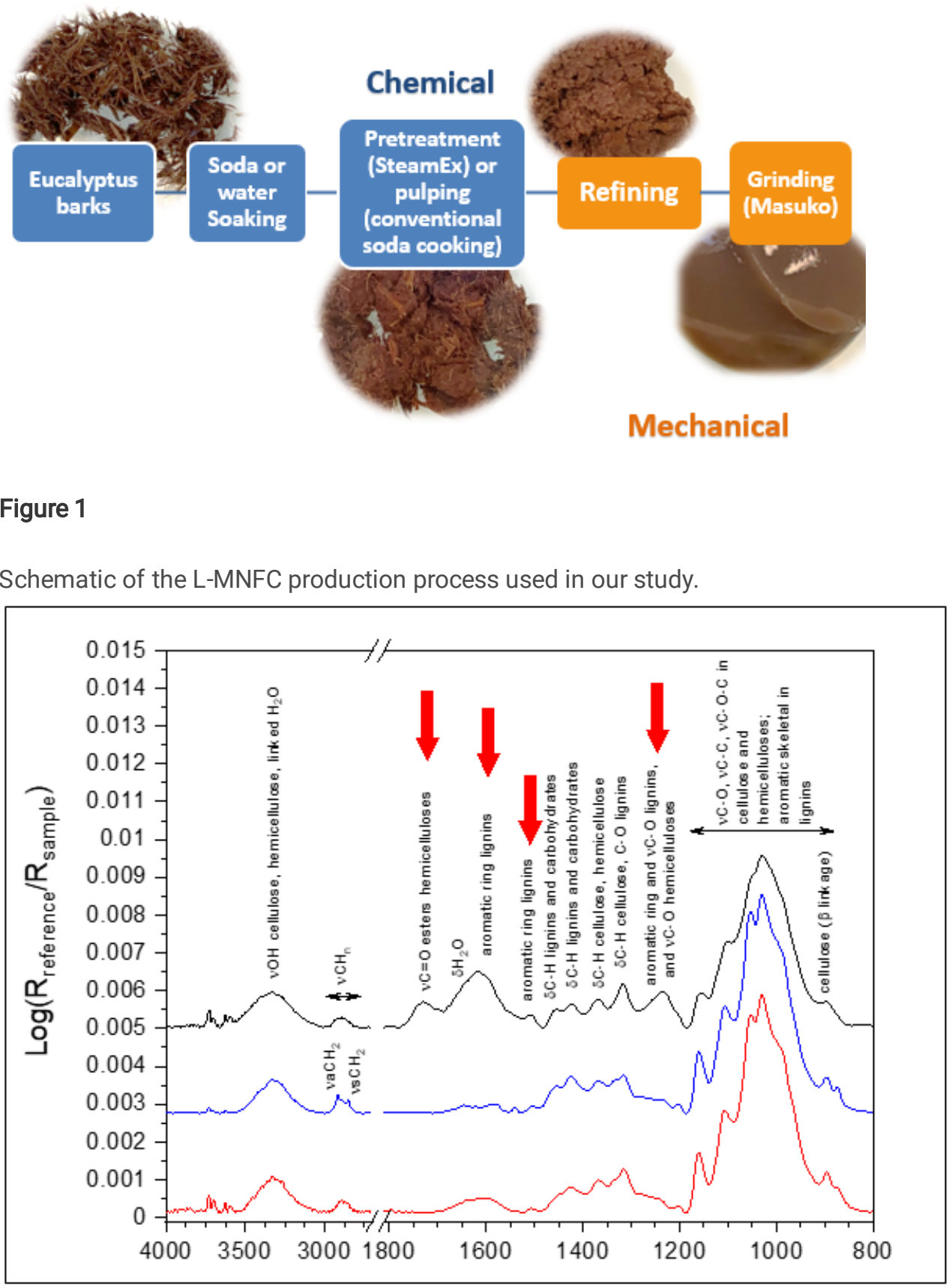

Figure 2

IR-ATR spectra of raw Eucalyptus globulus barks (dark), soda cooking in autoclave (red), and alkaline SteamEx (blue). Principal assignments are indicated. The spectra are normalized to one from region 1800-800 cm 1. For clarity, spectra were shifted vertically. Key: $n$, stretching vibration; $d$, bending vibration. 


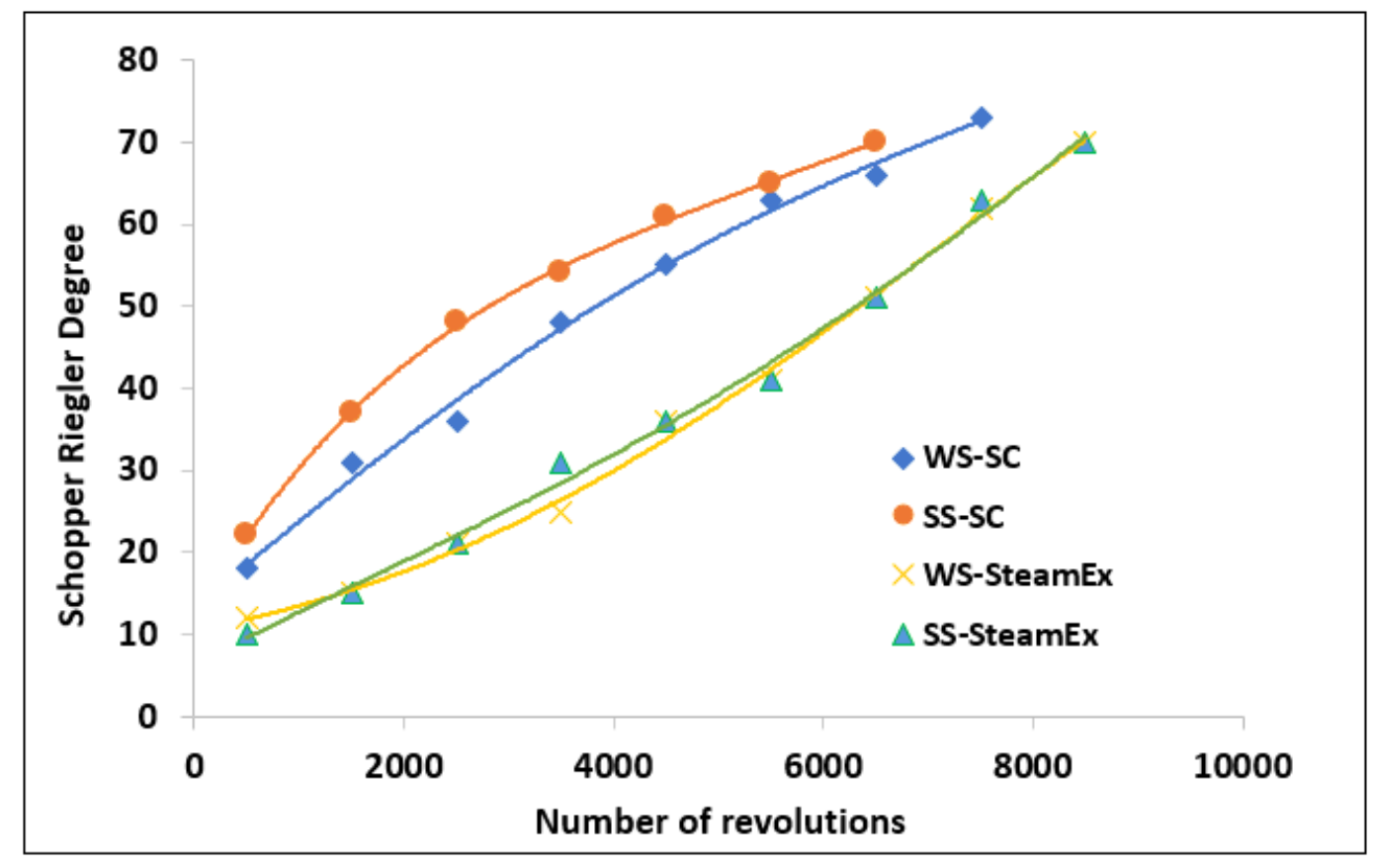

Figure 3

Evolution of Schopper Riegler degree for different pulps with the number of revolutions of the PFI mill disk. Key: WS, water swelling; SS, soda swelling; SC, conventional soda cooking in autoclave.

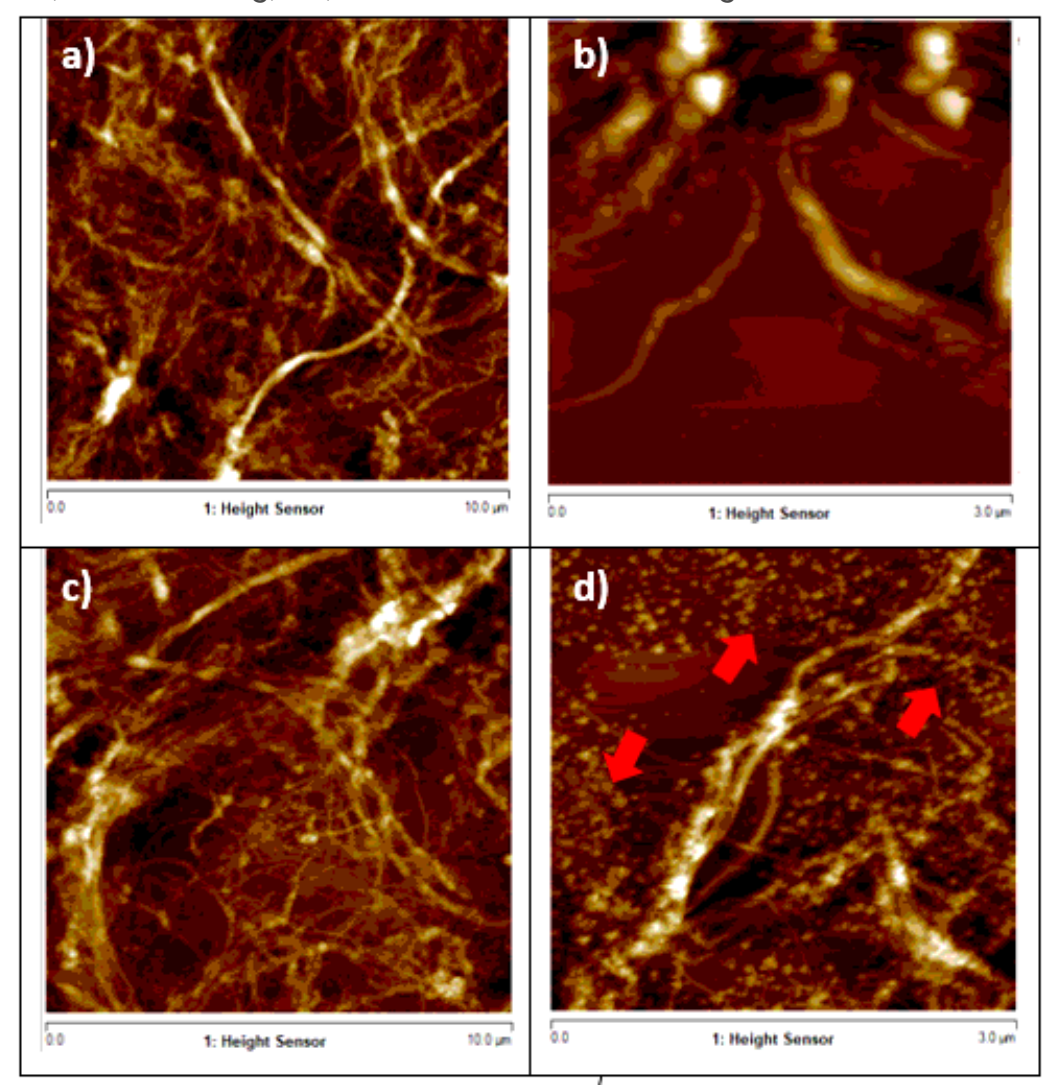

Figure 4

AFM height images of (a) WS-SC $10 \mu \mathrm{m} \times 10 \mu \mathrm{m}$, (b) WS-SC $3 \mu \mathrm{m} \times 3 \mu \mathrm{m}$, (c), WS-SteamEx $10 \mu \mathrm{m} \times 10 \mu \mathrm{m}$ and (d) WS-SteamEx 3 $\mu \mathrm{m} \times 3 \mu \mathrm{m}$. Lignin droplets are marked by red arrows in d. Key: WS, water swelling; SS, soda swelling; SC, conventional soda cookina in autoclaves. 


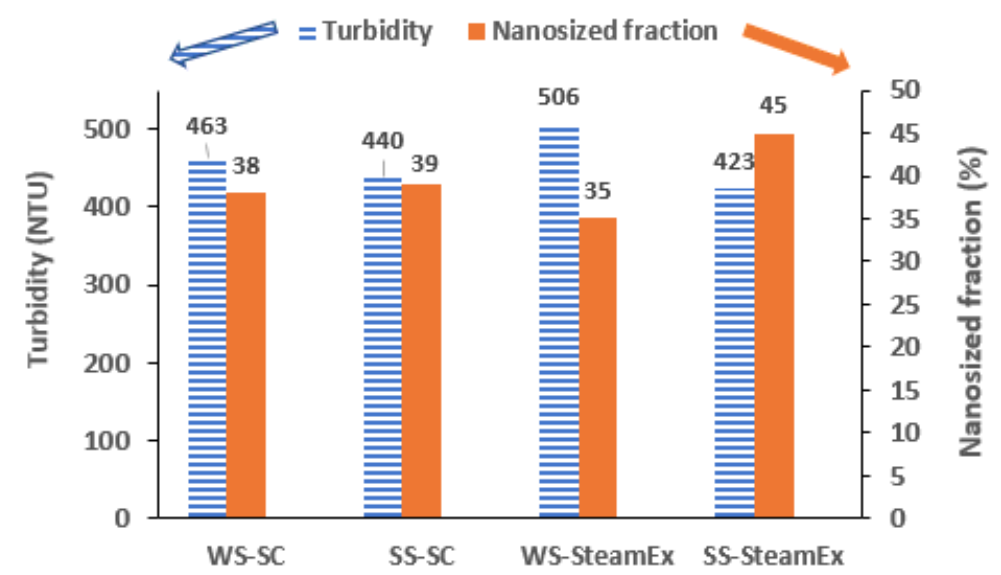

\section{Figure 5}

Turbidity and nanosized fraction of different L-MNFC suspensions. Key: WS, water swelling; SS, soda swelling; SC, conventional soda cooking.

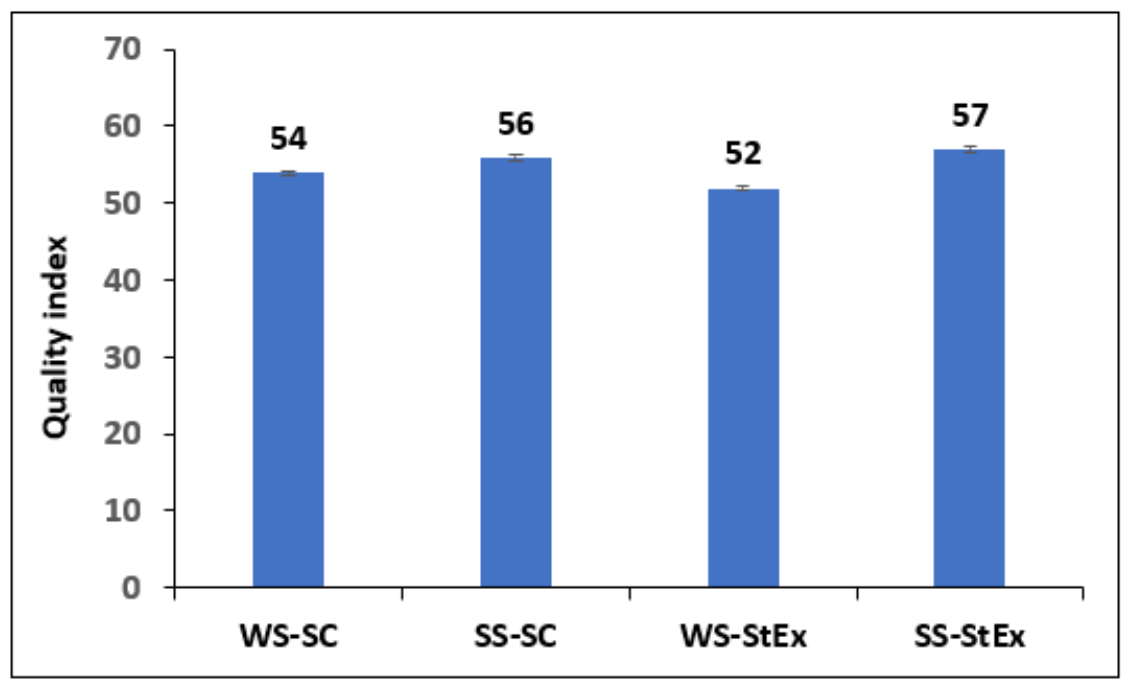

\section{Figure 6}

Quality index of L-MNFC suspensions. Key: WS, water swelling; SS, soda swelling; SC, conventional soda cooking. 